\title{
Effect of Microwave Heating on the Dielectric Properties and Components of Iron-Fortified Milk
}

\author{
Xiao-shu Tang, ${ }^{1,2,3}$ Da-ming Fan, ${ }^{1,3,4}$ Feng Hang, ${ }^{1}$ Bo-wen Yan, ${ }^{3,4}$ \\ Jian-xin Zhao, ${ }^{1,2,3}$ and Hao Zhang ${ }^{1,2,3}$ \\ ${ }^{1}$ State Key Laboratory of Dairy Biotechnology, Technology Center, Bright Dairy \& Food Co. Ltd., Shanghai 200436, China \\ ${ }^{2}$ National Engineering Research Center for Functional Food, Jiangnan University, Wuxi 214122, China \\ ${ }^{3}$ State Key Laboratory of Food Science and Technology, School of Food Science and Technology, Jiangnan University, \\ Wuxi 214122, China \\ ${ }^{4}$ Collaborative Innovation Center of Food Safety and Quality Control in Jiangsu Province, Wuxi 214122, China
}

Correspondence should be addressed to Jian-xin Zhao; jxzhao@jiangnan.edu.cn

Received 9 June 2017; Revised 27 October 2017; Accepted 8 November 2017; Published 6 December 2017

Academic Editor: Susana Fiszman

Copyright (C) 2017 Xiao-shu Tang et al. This is an open access article distributed under the Creative Commons Attribution License, which permits unrestricted use, distribution, and reproduction in any medium, provided the original work is properly cited.

With the iron-fortified milk as research object, this paper makes a research on the influence of iron on the dielectric properties and wave absorption properties and effect of nutritional components, such as casein and whey protein in milk, and thermostability in the process of microwave heating, and rapid heat transfer method in ferrous gluconate-milk and ferrous chloride-milk, respectively. The results show that the iron of ionic form has greater influence to convert microwave to heat energy and the effect of microwave absorption properties was greater for ferrous chloride than for ferrous gluconate at high concentration. The effect of different forms of iron on the composition of milk was different, and the composition of milk systems was more stable by microwave heating, but the rapid heat transfer method is superior in the aim of increasing the nutritional value of milk. The ferrous gluconate-milk system has a better thermal stability than ferrous chloride-milk system. From the aspect of dielectric induction, the paper discovers the response rules of iron and evaluates the microwave thermal safety of the traditional and the iron-fortified products by microwave heating.

\section{Introduction}

Iron is an essential trace element and a key component of red blood cells and myoglobin. Iron deficiency can lead to anemia, weakening the immune system and the ability to fight infection. As one of the oldest naturally occurring drinks, cow's milk is effectively a form of liquid food and contains the most complete and highly concentrated set of nutrients of any drink except human breast milk. In particular, milk contains an appropriate amount of the trace element iron, making it a suitable food for promoting strength [1].

In the processing of dairy products, the heat treatment of milk is necessary. While heating can increase the shelf-life and improve the safety of dairy products, traditional methods lead to the loss of milk protein [2]: for example, UHT milk heating increases the possibility of protein coagulation [3]. Considering the sheer number and diversity of domestic milk producers and the poor quality of raw milk, the study of heat treatment of milk is highly necessary. As a common means of rapid heating, microwave treatment can prevent the interaction of casein phosphate groups with metal ions through microwave-induced vibration and thereby impede protein coagulation, owing to the high dielectric response characteristic of the ions present in milk [4]. While indirect heating with UHT causes around $65 \%$ denaturation of whey protein [5], direct heat treatment methods such as steam injection are much less disruptive, causing only about $35 \%$ denaturation [6]. Thus, as a direct heating method, the development of new technology based on microwave sterilization has realistic significance.

The dielectric effect is the response of the bound charge in molecules to an applied electric field and is an inherent property of dielectric materials [7]. The main parameters used to express dielectric properties are the dielectric constant $\varepsilon^{\prime}$ and 


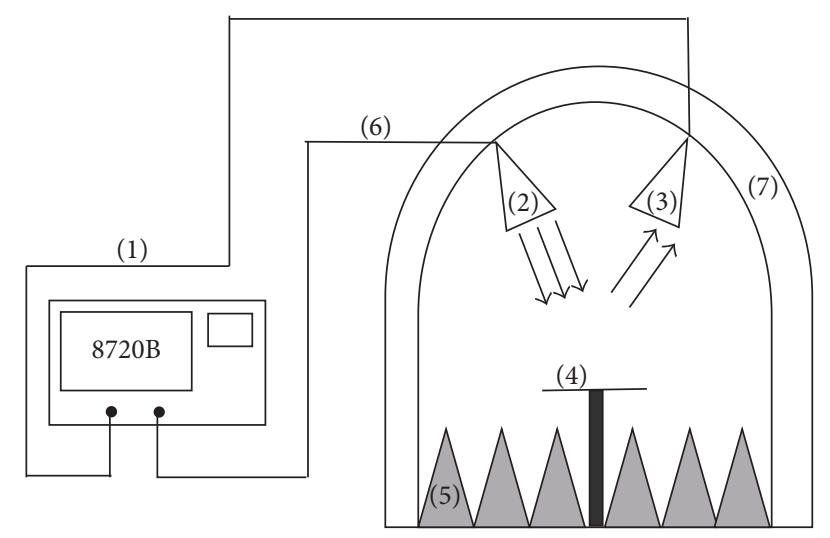

FIGURE 1: Schematic of the test system using the arch method ((1) network analyzer, (2) transmitter, (3) receiver, (4) reflecting plate, (5) pyramidal absorber, (6) transmission line, and (7) arch beam).

dielectric loss factor $\varepsilon^{\prime \prime}[8]$. Milk is a heterogeneous colloid dispersion. Colloid protein and fat particles are dispersed in water containing salt, lactose, and whey protein. For a heterogeneous material, the different phases have different dielectric parameter values, and charge accumulates at the phase boundaries, creating polarization between the two phases at the interface. Induced changes of the dielectric parameters of milk are mainly caused by dipoles, electrons, and atomic polarization and the Wagner effect in the nonuniform material $[9,10]$.

This study investigated the effects on the nutritional components of liquid milk, such as casein and whey protein, during the process of microwave heating, a method based on dielectric induction. The response of iron during microwave heating was characterized, and the thermal safety of traditional and iron-fortified products during microwave heating was evaluated. This study will provide guidance on the health aspects of dairy consumption, a reference for consumers for the objective evaluation of the safety of microwaveheated food, and a theoretical foundation for the industrial application of microwaves in dairy processing.

\section{Materials and Methods}

2.1. Preparation of Iron-Fortified Milk. To study the influence of the chemical form and the concentration of iron on the dielectric properties of milk, two iron sources were selected: ferrous gluconate and ferrous chloride, both analytically pure, and they were purchased from chemical reagents of national pharmaceutical group of China. The pure milk (UHT milk, $250 \mathrm{~mL}$, shelf-life for 6 months) was purchased from Bright Dairy \& Food Co., Ltd. A high-quality milk rich in iron was also chosen. Iron was added in its preparation (patent number: CN $103651846 \mathrm{~A}$ ) to make an iron concentration gradient of $1.0 \mathrm{mg} / 100 \mathrm{~g}, 1.5 \mathrm{mg} / 100 \mathrm{~g}, 2.0 \mathrm{mg} / 100 \mathrm{~g}, 2.5 \mathrm{mg} / 100 \mathrm{~g}$, and a blank sample.

2.2. Measurement of Dielectric Properties. The system used to measure the electromagnetic characteristics of the samples for data acquisition comprised a vector network analyzer (Agilent, USA), high-temperature probe, cable ends, and software to measure dielectric characteristics. It was necessary to calibrate the probe against air, water (at a known temperature), and a metallic short circuit at 3 o'clock to ensure that the system error was minimal. Samples were blended before every measurement, following which the test frequency range was selected $(2.4$ to $2.5 \mathrm{GHz})$, and then the real component (dielectric constant) $\varepsilon^{\prime}$ and imaginary component (dielectric loss) $\varepsilon^{\prime \prime}$ of the complex dielectric constant were read by the online detection software. Each sample was tested in parallel three times, and the average was taken. If the data repeatability fell outside the range of plus or minus $5 \%$, the system was recalibrated and the measurements were repeated. Thus, the data recorded were the dielectric constant and dielectric loss of each sample at $2.45 \mathrm{GHz}$.

2.3. Measurement of Absorption Properties. The electromagnetic wave-reflection rate of the milk system was tested using the improved bow method [11, 12] (military specification GJB2038-94) to test the absorption performance of the materials at frequencies from 2.3 to $2.5 \mathrm{GHz}$. The test system was put in a microwave-equipped dark room, including two gain antennas on the metal reference surface. The transmitting antenna and receiving antenna were fixed above the vertical symmetry position of the tested pool of material and the object was put on the center position of the bow frame. In this test system, signals were emitted from the transmitting antenna on the vector network analyzer and then reflected by a metal plate under the arch, received by the receiving antenna, and transferred to the vector network analyzer. Thus, a reference frequency (power) value was established. Then, the object under testing was put on the metal plate, and the reduction in received power was measured. The difference in received power between the metal plate and object under testing was transformed into a reflection loss in $\mathrm{dB}$. The experimental apparatus is shown in Figure 1 [13].

2.4. Rapid Conventional Heating. A thermostat (Thermo Fisher Scientific, MA, USA) with a Thermo Scientific AC200 oil bath (Pierce, IL, USA) at a temperature of $195^{\circ} \mathrm{C}$ was used for rapid heating. The milk sample $(50.00 \mathrm{~g})$ was stirred 


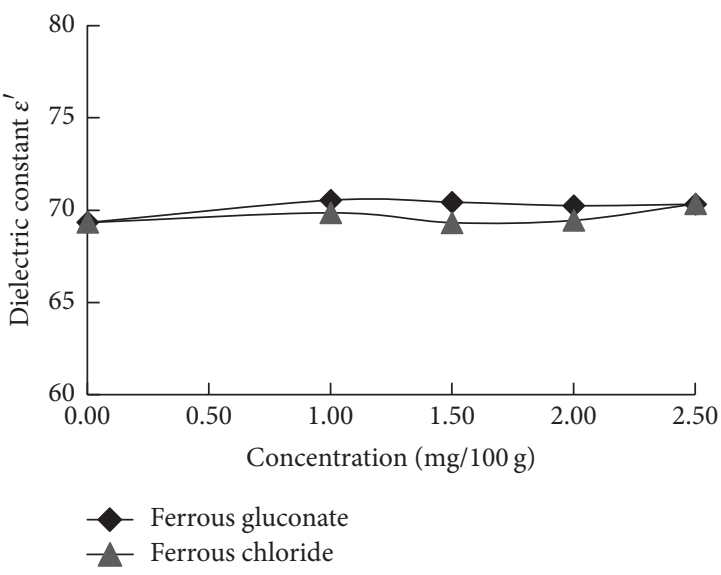

(a)

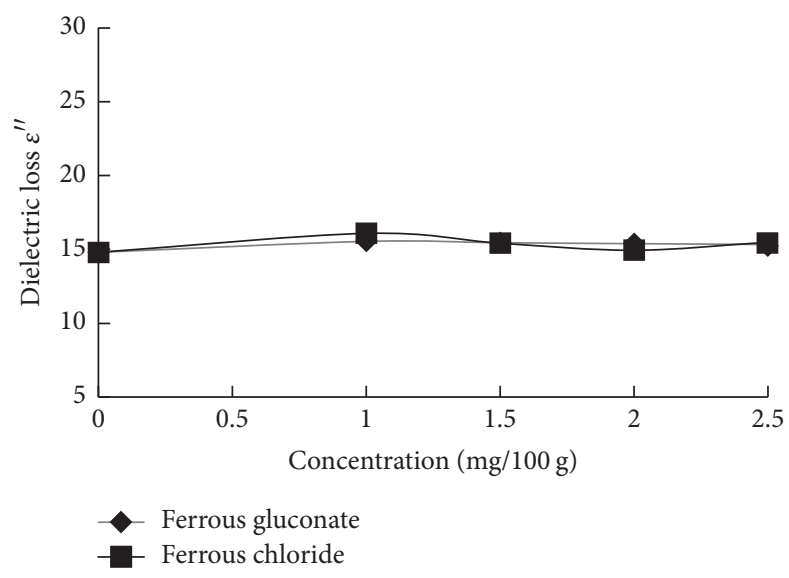

(b)

FIGURE 2: Dielectric constant and dielectric loss of iron-fortified milk.

constantly and the temperatures were measured online using an optical fiber probe. The system temperature was recorded in real time, and the temperature curve was drawn as a reference for setting the conditions of microwave heating. Then, the sample was immediately put into an ice bath to stop the gelatinization process.

2.5. Microwave Heating. Samples with a mass of $4 \mathrm{~g}$ were placed into a quartz test tube with an inner diameter of $1.2 \mathrm{~cm}$. The test tube was put in a polyester casing with zero electromagnetic absorption and then placed in the cavity sample pool of a Multi-SYNTH microwave generator (Milestone Company, Italy) operating in single microwave mode, setting the microwave frequency at $2.45 \mathrm{GHz}$. Using an infrared temperature probe, the temperature inside the tube was monitored in real time. The microwave generator ensured the uniformity of the samples with respect to radiation and temperature distribution in equilibrium by adjusting the vibration frequency of the sample pool, thus avoiding errors caused by uneven radiation, with the vibration frequency set to $10 \%$. The step-by-step program was chosen for heating control. The heating time and heating conditions were determined according to the temperature curve from the rapid transmission heating method. When the sample temperature reached the preset temperature, microwave heating was stopped immediately. To prevent the sample temperature from continuing to rise, the processed sample was immediately put into an ice-cooled bath.

2.6. Milk Composition Analysis. To analyze and compare the compositions of the iron-milk complex systems following the rapid transmission and microwave heating methods, a multifunction milk analyzer (FOSS MilkoScan, Danish Foss Company) was used. From each of the rapid-heated and microwave-heated samples, $40 \mathrm{~mL}$ aliquots were placed into a beaker and their compositions analyzed. The tested components included fat content (Fat, \%), crude protein content (Cru. Prot., \%), true protein content (Tru. Prot., \%), lactose content (Lactose, \%), non-fat solids content (SnF, \%), total solids content (Ts, \%), and freezing point (FPT, ${ }^{\circ} \mathrm{C}$ ) $[14,15]$.

2.7. Particle Size Analysis [16]. Particle size analysis was carried out on the experimental samples, using a BT-9300H laser particle size distribution instrument (Bettersize Instruments Ltd., China) equipped with a scattered BT-600 circulating pump (Dan Dong Bettersize Instruments Ltd., China). Samples under test included the blank group, the milk samples treated by heat transfer, and the milk samples treated by microwave heating. Before the tests, the samples were kept at $20 \pm 1^{\circ} \mathrm{C}$ for $30 \mathrm{~min}$ to ensure constant sample temperatures, with no dilution of any samples. A suitable amount of each sample was added to the sample pool (a dispersion medium based on water) and then tested during ultrasonic dispersion at a rotating speed of 320 RPM. This yielded the particle size distribution diagrams. The measurement was performed three times for each sample, and the average values were used for subsequent analysis.

\section{Results and Discussion}

\subsection{Influence of Iron on the Dielectric Properties and Wave Absorption Performance of Milk}

3.1.1. Dielectric Properties of Iron-Fortified Milk. The dielectric constant $\varepsilon^{\prime}$ and the dielectric loss factor $\varepsilon^{\prime \prime}$ of the different iron-milk composite systems at $2.45 \mathrm{GHz}$ at room temperature were studied. The results are shown in Figure 2.

It can be seen from Figure 2(a) that the dielectric constant $\varepsilon^{\prime}$ of the iron-milk composite system did not change significantly with iron concentration at $2.45 \mathrm{GHz}$ at room temperature. At a given iron concentration, the different forms of iron also had no obvious effect on the dielectric constant. It can be seen from Figure 2(b) that the dielectric loss factor $\varepsilon^{\prime \prime}$ slightly fluctuated with the increase of iron concentration but did not change appreciably. The different forms of iron at a given iron concentration had a slight influence on the dielectric loss factor. Compared with the 


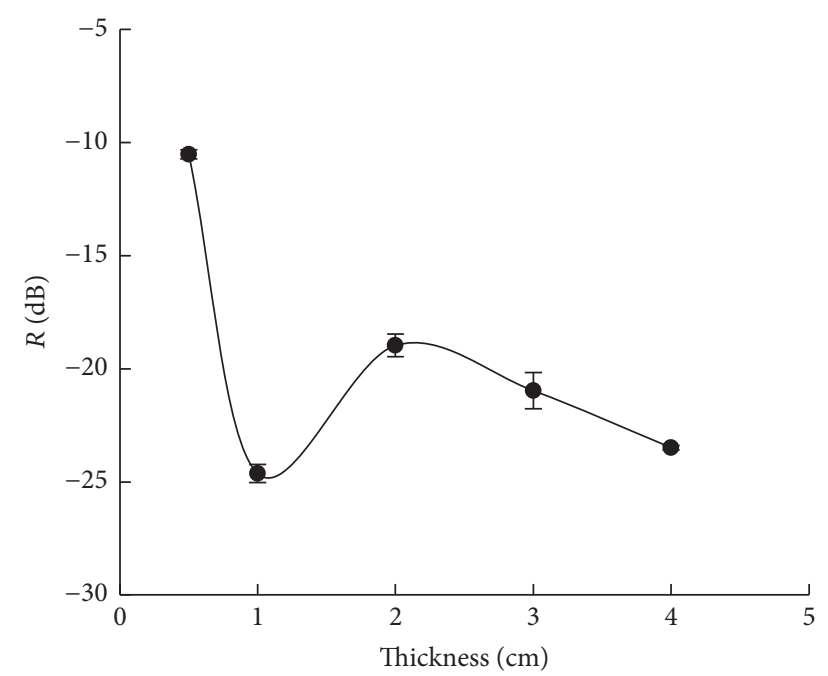

FIGURE 3: Microwave-absorbing properties of blank milk in containers of different thickness.

fluctuations seen for ferrous chloride, the dielectric loss as a function of the ferrous gluconate concentration was relatively stable.

The dielectric constant $\varepsilon^{\prime}$ characterizes the electrical properties affecting the absorption and transfer of energy and the ability of the iron-milk composite system to store electromagnetic waves. The dielectric loss factor $\varepsilon^{\prime \prime}$ represents the ability of the iron-milk composite system to consume electrical energy in the form of heat [17]. Therefore, with the increase of iron concentration, the system's ability to absorb and store the microwaves in the microwave field did not change, but its ability to convert the absorbed microwave energy into heat energy fluctuated slightly. In addition, the presence of iron in different forms had no effect on its ability to absorb and store microwaves in the microwave field, while it did affect its ability to convert the absorbed microwave energy into thermal energy, which was greater in the presence of ionic iron (ferrous chloride).

3.1.2. Microwave-Absorbing Properties of Iron-Fortified Milk. A blank sample was used to determine the reference values of the wave absorption performance. Milk was placed in containers of different thickness, and the wave absorption performances of the milk were measured. The results are shown in Figure 3.

The figure shows that, in the range of $2.3-2.5 \mathrm{GHz}$, based on a $2.45 \mathrm{GHz}$ frequency, with increasing container thickness the wave absorption performance of the blank milk first rises and then decreases. The peak absorption value is $24.627 \mathrm{~dB}$ (with a container thickness of $1 \mathrm{~cm}$ ). It can be concluded that the absorbing power of the material does not have a simple linear relationship with its thickness, but rather there is an optimum thickness at any specified frequency. The subsequent experiments were conducted using containers of $1 \mathrm{~cm}$ thickness to inspect the influence of the chemical form and concentration of iron on the absorbing performance of the system.

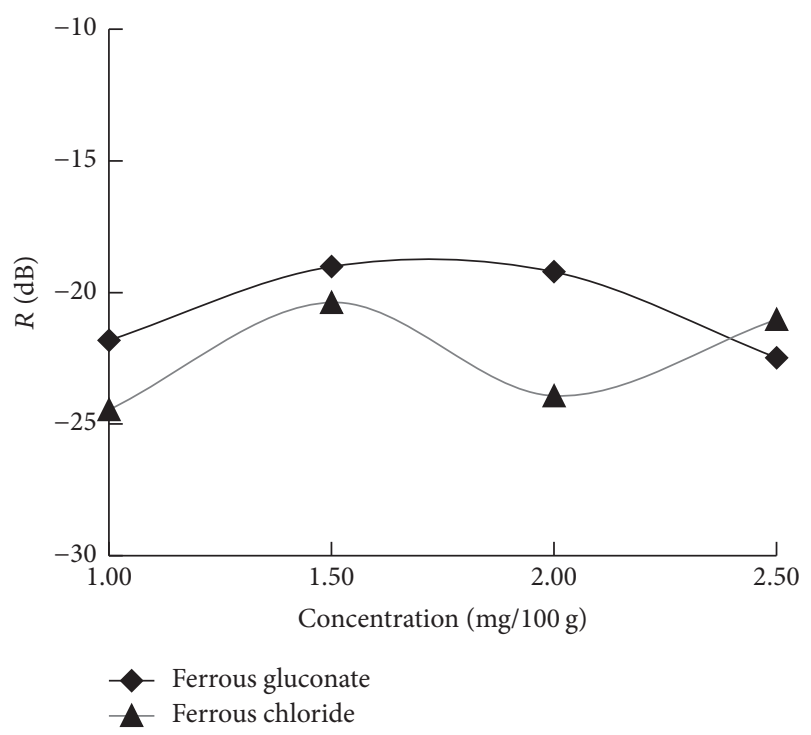

FIgURE 4: Absorbing properties of iron-fortified system at $1 \mathrm{~cm}$ container thickness.

It can be seen from Figure 4 that as the iron concentration increased from $1 \mathrm{mg} / 100 \mathrm{~g}$ to $2.5 \mathrm{mg} / 100 \mathrm{~g}$ at $2.45 \mathrm{GHz}$, the reflection loss of the iron-milk composite system fluctuated slightly, but no significant changes occurred. The effects of the different forms of iron were compared. When increasing the iron concentration from $1 \mathrm{mg} / 100 \mathrm{~g}$ to $1.5 \mathrm{mg} / 100 \mathrm{~g}$, the reflection loss slightly decreased in the presence of both ferrous gluconate and ferrous chloride. However, when increasing the iron concentration from $1.5 \mathrm{mg} / 100 \mathrm{~g}$ to $2.5 \mathrm{mg} / 100 \mathrm{~g}$, the effect on the reflection loss differed between the ferrous gluconate and ferrous chloride systems: in the former, the reflection loss fluctuated slightly but not significantly, while in the latter, the reflection loss fluctuated greatly.

In general, the iron concentration had little effect on the microwave absorption properties of the system. The chemical form of iron, that is, ferrous gluconate or ferrous chloride, had an effect on the microwave absorption properties, but the effect was weak and the two systems responded similarly to the increase in iron concentration from $1 \mathrm{mg} / 100 \mathrm{~g}$ to $1.5 \mathrm{mg} / 100 \mathrm{~g}$. The effect of changing the iron concentration between $1.5 \mathrm{mg} / 100 \mathrm{~g}$ and $2.5 \mathrm{mg} / 100 \mathrm{~g}$ was greater for ferrous chloride than for ferrous gluconate.

\subsection{Changes in the Composition of Iron-Fortified Milk in the Microwave Field}

3.2.1. Fitting of Microwave Heating Process [18, 19]. In the process of microwave heating a material, the microwaves exert both thermal and nonthermal effects on the material simultaneously. To enable a detailed study of the effects of microwave heating on the material structure, an experiment was performed using high-speed oil-bath heating combined with microwave heating to generate data for fitting, allowing us to isolate the nonthermal effect of microwaves on the iron-milk composite system. 


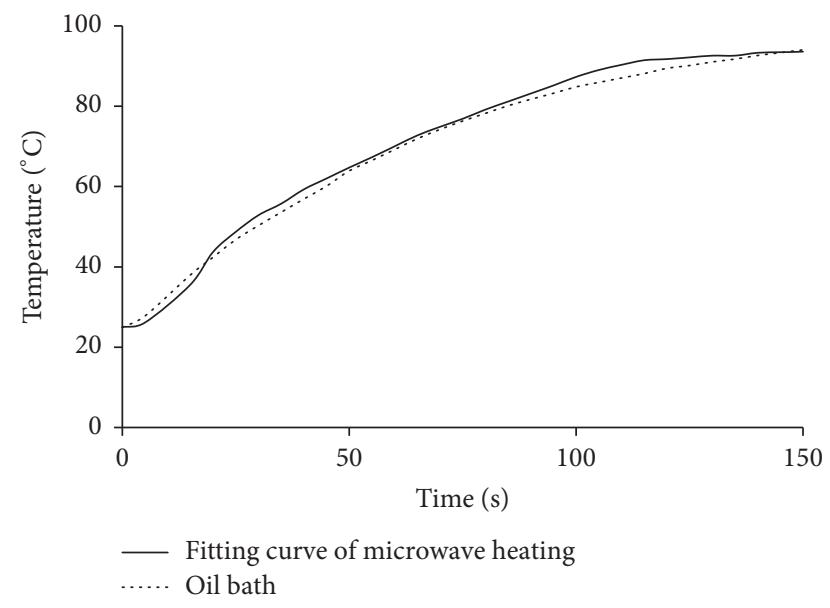

FIGURE 5: Rapid heating and fitting curves of microwave heating of blank milk.

To achieve this, the microwave power was adjusted at temperatures above $95^{\circ} \mathrm{C}$ to ensure that the two temperature curves eventually coincided. To simulate the rapidheating conditions in the oil bath, which was set at $195^{\circ} \mathrm{C}$, the microwave heating program was set at $72 \mathrm{~W}$ for $15 \mathrm{~s}$, $39 \mathrm{~W}$ for $50 \mathrm{~s}, 33 \mathrm{~W}$ for $45 \mathrm{~s}$, and $31 \mathrm{~W}$ for $45 \mathrm{~s}$. The two temperature-time curves are shown in Figure 5, for which the multiple correlation coefficient obtained from the function "corrcoef" in MATLAB was 0.9982.

3.2.2. Effect of Different Forms of Iron on the Composition of Milk. Samples of milk containing ferrous gluconate or ferrous chloride, both at a concentration of $2.00 \mathrm{mg} / 100 \mathrm{~g}$, were gradually heated from room temperature to $45^{\circ} \mathrm{C}, 65^{\circ} \mathrm{C}$, and $95^{\circ} \mathrm{C}$. The changes in composition were measured for the two iron-milk complex systems produced using different forms of iron supplement. The data are summarized in Table 1.

From the data in Table 1, it can be concluded that, under the same heating intensity, compared with ferrous gluconate, supplementation with ferrous chloride had a more pronounced effect on the fat content in milk, causing it to decrease. The addition of ferrous chloride also slightly decreased the content of crude protein. The impact of both iron sources on real protein was extremely small, but the lactose content was higher in the ferrous gluconate-milk system. The ferrous gluconate-milk system also had a higher SnF content. The Ts content of the ferrous gluconate-milk system was slightly higher than that for ferrous chloride, but with the increase of temperature, the difference between them decreased. For both iron sources, the freezing point of milk fluctuated within the recommended range $\left(508-546 \mathrm{~m}^{\circ} \mathrm{C}\right)$ [15].

3.2.3. Effect of Different Concentrations of Ferrous Gluconate on the Composition of Milk. Samples of ferrous gluconatemilk of different iron concentrations were microwave-heated to $45^{\circ} \mathrm{C}$ and $95^{\circ} \mathrm{C}$. Table 2 shows that, after the microwave heating process, the concentration of iron considerably influenced the contents of lactose and fat in the milk composite systems but had relatively slight effects on the protein content, freezing point, and other properties.

In the samples microwave-heated to both $45^{\circ} \mathrm{C}$ and $95^{\circ} \mathrm{C}$, the fat content consistently declined with the increase of the concentration of iron, the reason for which needs further research and analysis.

In the sample microwave-heated to $45^{\circ} \mathrm{C}$, the lactose content increased with increasing concentration of iron, but no such trend was apparent for the sample heated to $95^{\circ} \mathrm{C}$.

\subsubsection{Effect of Different Heating Modes on Composition of} Iron-Fortified Milk. Samples of ferrous gluconate-milk with an iron concentration of $2 \mathrm{mg} / 100 \mathrm{~g}$ were heated by rapid transmission and by microwave treatment, to compare the composition of the milk-iron complex systems treated by the different heating modes.

Figure 6 shows the change of the composition of the ferrous gluconate-milk system when heated to $45^{\circ} \mathrm{C}$ and $95^{\circ} \mathrm{C}$ by the two methods. It can be seen that, at $45^{\circ} \mathrm{C}$, the contents of Fat, Cru. Prot., Tru. Prot., Lactose, and FPT were essentially the same under the microwave heating and rapid heat transfer methods. However, under the rapid heat transfer method, the SnF and Ts contents were slightly higher than those of the microwave heating method. At $95^{\circ} \mathrm{C}$, the fat contents under microwave heating and rapid heat transfer method were again essentially the same. However, the contents of Cru. Prot., Tru. Prot., Lactose, SnF, Ts, and FPT under the rapid heat transfer method were higher than that of the microwave heating method. In particular, SnF and Ts differed significantly. This shows that these components are unstable under the rapid heat transfer method, but not under the microwave heating method. Therefore, microwave heating is not expected to affect the composition of milk systems significantly after heating to high temperature. However, considering the aim of increasing the nutritional value of milk, the rapid heat transfer method is superior to microwave heating.

The following conclusions can be drawn. When milk is heated to moderate or high temperature, the effect of microwave heating on its chemical composition is relatively small; with respect to the aim of increasing the nutritional value of milk, rapid heat transfer is more desirable than microwave heating. However, microwave heating is simpler and more convenient than rapid heat transfer. If the milk is to be heated more than once, microwave heating will be preferable.

\subsection{Thermostability of Iron-Fortified Milk in Microwave Field}

3.3.1. Thermostability of Milk during Heating. As can be seen from Table 3, the particle size distributions of the blank milk treated with the same microwave method to different temperatures varied significantly. Taking the ferrous gluconate-milk system as an example, with the increase of the degree of heat treatment, the particle size distribution of the milk system shifted to larger particles, although only $10.74 \%$ of the particle sizes reached $10-100 \mu \mathrm{m}$.

Heating to $95^{\circ} \mathrm{C}$ had the greatest effect on the particle size distribution, so this temperature was used in the following studies to investigate the effects of different iron forms, iron 


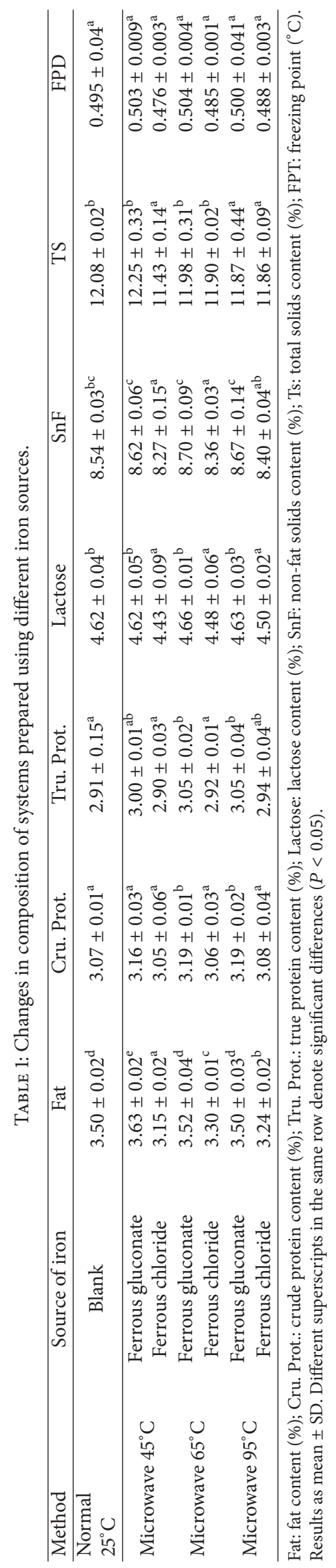




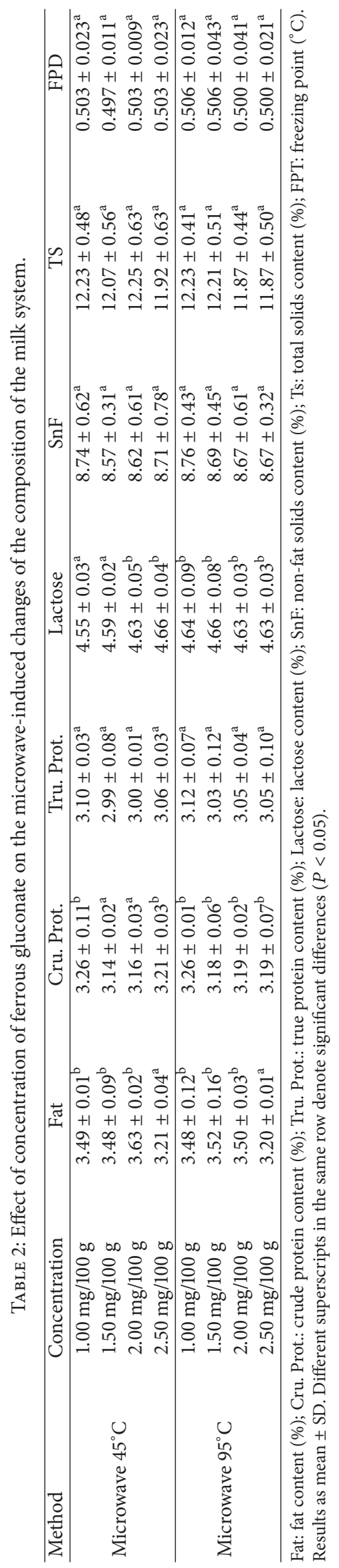


TABLE 3: Percentage of particle size of ferrous gluconate-milk under different temperature.

\begin{tabular}{lcccc}
\hline Sample & Temperature & $0-1 \mu \mathrm{m}$ & $1-10 \mu \mathrm{m}$ & $10-100 \mu \mathrm{m}$ \\
\hline \multirow{3}{*}{ Blank milk } & $25^{\circ} \mathrm{C}$ & $90.95 \pm 0.23^{\mathrm{d}}$ & $5.55 \pm 0.31^{\mathrm{a}}$ & $3.50 \pm 0.56^{\mathrm{a}}$ \\
& $45^{\circ} \mathrm{C}$ & $71.68 \pm 0.59^{\mathrm{a}}$ & $12.38 \pm 0.42^{\mathrm{c}}$ & $15.94 \pm 0.60^{\mathrm{d}}$ \\
& $65^{\circ} \mathrm{C}$ & $71.69 \pm 0.88^{\mathrm{a}}$ & $12.59 \pm 0.74^{\mathrm{c}}$ & $15.72 \pm 0.62^{\mathrm{d}}$ \\
Ferrous gluconate & $95^{\circ} \mathrm{C}$ & $76.33 \pm 0.45^{\mathrm{c}}$ & $10.66 \pm 0.51^{\mathrm{b}}$ & $13.01 \pm 0.54^{\mathrm{c}}$ \\
& $45^{\circ} \mathrm{C}$ & $73.69 \pm 0.21^{\mathrm{b}}$ & $12.44 \pm 0.28^{\mathrm{c}}$ & $13.87 \pm 0.34^{\mathrm{c}}$ \\
& $65^{\circ} \mathrm{C}$ & $73.64 \pm 0.15^{\mathrm{b}}$ & $12.49 \pm 0.57^{\mathrm{c}}$ & $13.87 \pm 0.24^{\mathrm{c}}$ \\
\hline
\end{tabular}

Results as mean \pm SD. Different superscripts in the same row denote significant differences $(P<0.05)$.
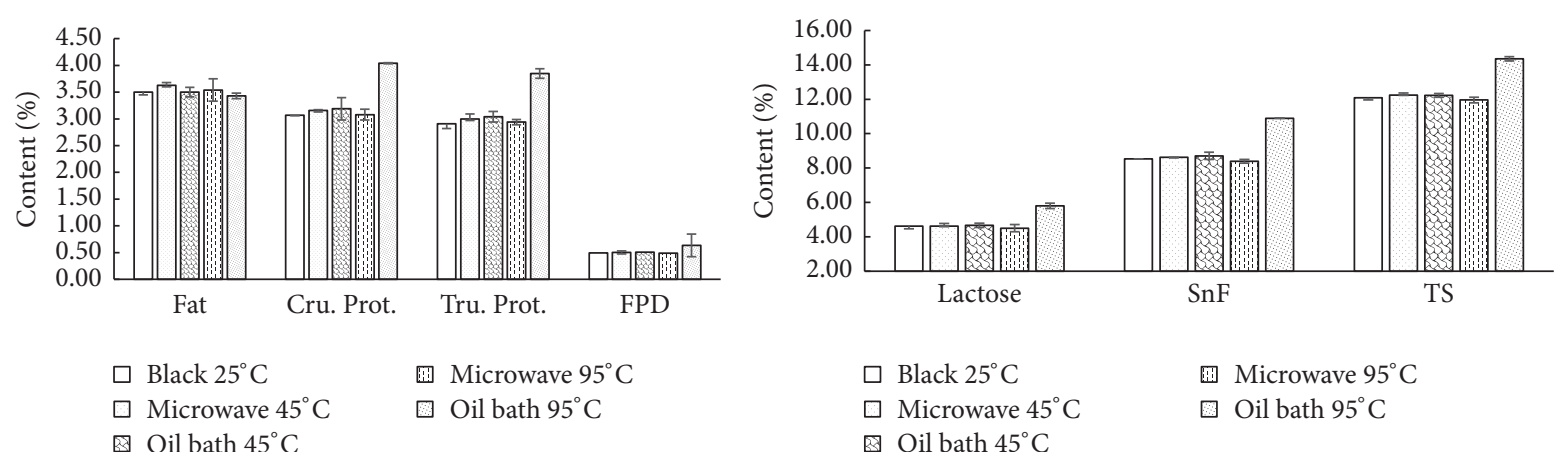

Figure 6: Composition changes of ferrous gluconate-milk heated to $45^{\circ} \mathrm{C}$ and $95^{\circ} \mathrm{C}$. Fat: fat content (\%); Cru. Prot.: crude protein content (\%); Tru. Prot.: true protein content (\%); Lactose: lactose content (\%); SnF: non-fat solids content (\%); Ts: total solids content (\%); FPT: freezing point $\left({ }^{\circ} \mathrm{C}\right)$.

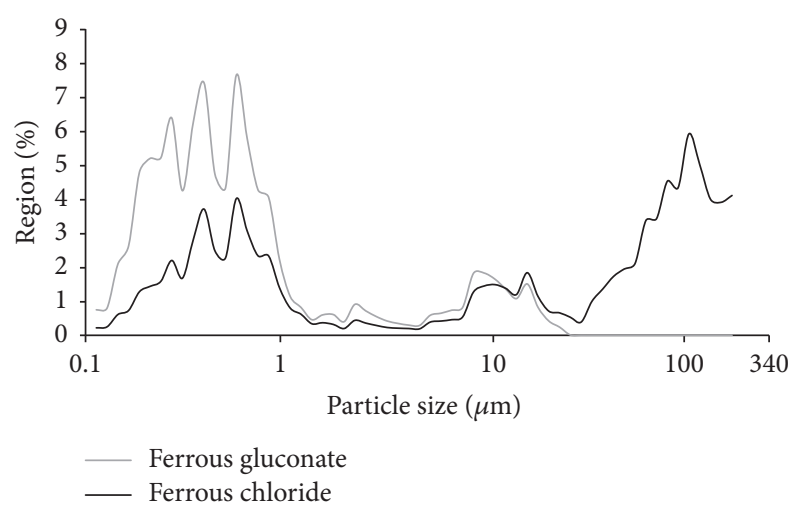

FIGURE 7: Particle size distribution after heating at $95^{\circ} \mathrm{C}$ for different iron forms.

concentrations, and heating modes on the thermal stability of milk under a microwave field.

\subsubsection{Effect of Different Iron Forms on Milk Thermostability.} The particle size distributions of the ferrous gluconate-milk and ferrous chloride-milk systems when heated to $95^{\circ} \mathrm{C}$ are shown in Figure 7. Particles in the size range of $0.1-1 \mu \mathrm{m}$ were relatively numerous in the ferrous gluconate-milk system but formed only a small fraction of the particles of the ferrous chloride-milk system. The content of particles in the range of $1-100 \mu \mathrm{m}$ was low in both systems. It is noteworthy that the ferrous gluconate-milk system contained almost no particles of more than $100 \mu \mathrm{m}$, while in the particle size distribution of the ferrous chloride-milk system, the radius (half diameter) of the majority of particles fell within the $100-340 \mu \mathrm{m}$ range. This indicates that the effect of ferrous chloride on the thermal stability of the milk system was much greater than that of ferrous gluconate, as ferrous chloride resulted in a large amount of protein coagulation and considerable flocculation.

The addition of ferrous gluconate can make the organizational structure of milk more uniform; because of its buffer effect, it stabilizes the $\mathrm{pH}$ of the system [16], which reduces the impact of the addition of ferrous gluconate on the thermal stability of the milk system. In contrast, when ferrous chloride is used as the iron source, the iron is present in the ionic state, disrupting the original salt balance of the system in several ways: $\alpha$-s1-casein is adsorbed onto the free metal ions, colloidal calcium phosphate becomes more soluble, casein loses its electrostatic charge and becomes agglutinated, the polymerization of fat and protein increases, and calcium also precipitates out after polymerization into larger particles. Internal aggregation occurs, and fine casein granules are gradually polymerized to form larger particles, making flocculation more severe [17]. All of these effects impair the quality of the ferrous chloride-milk composite system.

3.3.3. Effect of Iron Concentration on Thermostability of Milk. It can be seen from Figure 8 that the particle sizes of the ferrous gluconate-milk composite systems of different concentrations, after heating at $95^{\circ} \mathrm{C}$, were mostly within the range $0.1-1 \mu \mathrm{m}$, and the particle size distribution did not 


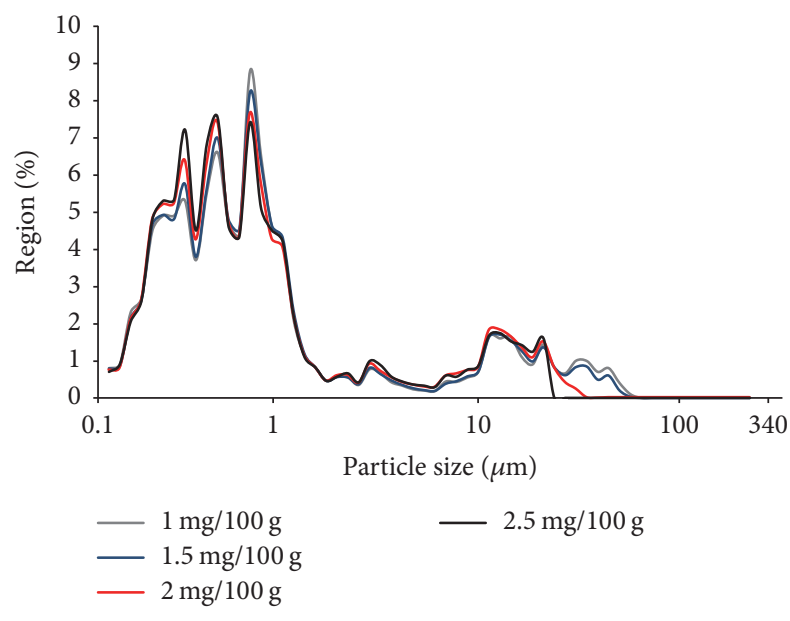

Figure 8: Particle size distribution after heating at $95^{\circ} \mathrm{C}$ for different concentrations of ferrous gluconate.

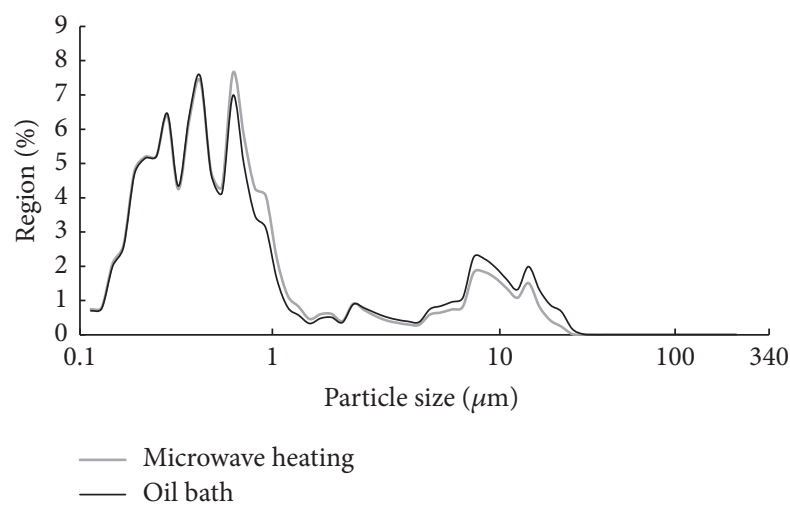

Figure 9: Particle size distribution of ferrous gluconate-milk after heating to $95^{\circ} \mathrm{C}$ using different methods.

significantly differ with concentration. Thus, the concentration of iron had no effect on the thermostability of the milk system in the microwave field, and at all concentrations the formation of large particles in the milk system was negligible and no precipitation of solids occurred.

3.3.4. Effect of Different Heating Methods on Thermostability of Iron-Fortified Milk. It can be seen from Figure 9 that the particle size distribution curves of the $1.5 \mathrm{mg} / 100 \mathrm{~g}$ ferrous gluconate-milk composite system under microwave heating and rapid conduction heat treatment to $95^{\circ} \mathrm{C}$ showed no significant difference, with particles in both systems mostly distributed in the ranges of $0.1-1 \mu \mathrm{m}$ and $10-100 \mu \mathrm{m}$. Both curves feature three peaks at essentially the same positions. Thus, the different heating methods had similar effects on the thermostability of the milk system.

\section{Conclusions}

The concentration and chemical form of iron have little impact on the microwave absorption and storage ability of iron-fortified milk. However, they do influence its ability to convert microwave to heat energy, which is greater when iron is present in ionic form. When the concentration is low, the different forms of iron have a relatively weak and constant impact on the ability of milk to absorb microwaves. However, at high concentration, ferrous chloride has a greater impact on the microwave-absorbing capability than ferrous gluconate.

After microwave heating, the form and concentration of iron significantly influence the fat content of the milk complex system, but their impact on the content of protein and Ts is small. When milk is heated to moderate or high temperature, its chemical composition is significantly altered by the rapid heat transfer method, but not by microwave heating.

Ferrous gluconate has relatively little effect on the thermal stability of the milk system and does not cause precipitation of coagulated protein. Fortification with ferrous chloride, however, significantly affects the thermal stability of the milk system and leads to serious coagulation precipitation. Under the microwave field, the different iron concentrations have almost no effect on the thermal stability of the milk system, and the fraction of large particles remains low, so that no coagulation precipitation occurs. The different heating methods have relatively little effect on the thermal stability of the milk system.

\section{Conflicts of Interest}

The authors declare that there are no conflicts of interest regarding the publication of this paper.

\section{Acknowledgments}

This study was supported by The Key Projects in the National Science \& Technology Pillar Program during the Twelfth Five-Year Plan Period (Grant no. 2014BAD04B03), the Open Project Program of State Key Laboratory of Dairy Biotechnology, Bright Dairy \& Food Co. Ltd. (SKLDB2015-001), and the program of "Collaborative Innovation Center of Food Safety and Quality Control in Jiangsu Province.”

\section{References}

[1] E. Santillán-Urquiza, M. Á. Méndez-Rojas, and J. F. Vélez-Ruiz, "Fortification of yogurt with nano and micro sized calcium, iron and zinc, effect on the physicochemical and rheological properties," LWT- Food Science and Technology, vol. 80, pp. 462469, 2017.

[2] H. Singh and A. Waungana, "Influence of heat treatment of milk on cheesemaking properties," International Dairy Journal, vol. 11, no. 4-7, pp. 543-551, 2001.

[3] C.-C. Chen and J.-F. Hsieh, "Microwave-assisted cross-linking of milk proteins induced by microbial transglutaminase," Scientific Reports, vol. 6, Article ID 39040, 2016.

[4] NACMCF, "Requisite scientific parameters for establishing the equivalence of alternative methods of pasteurization - national advisory committee on microbiological criteria for foods," Journal of Food Protection, vol. 69, no. 5, pp. 1190-1216, 2006.

[5] X. Y. Lan, J. Q. Wang, D. P. Bu, J. S. Shen, N. Zheng, and P. Sun, "Effects of heating temperatures and addition of reconstituted 
milk on the heat indicators in milk," Journal of Food Science, vol. 75, no. 8, pp. C653-C658, 2010.

[6] D. Agranovich, P. B. Ishai, G. Katz, D. Bezman, and Y. Feldman, "Microwave dielectric spectroscopy study of water dynamics in normal and contaminated raw bovine milk," Colloids and Surfaces B: Biointerfaces, vol. 154, pp. 391-396, 2017.

[7] X. Zhu and F. Kang, "Frequency- and temperature-dependent dielectric properties of goat's milk adulterated with soy protein," Food and Bioprocess Technology, vol. 8, no. 11, pp. 2341-2346, 2015.

[8] S. O. Nelson and S. Trabelsi, "Influence of water content on $\mathrm{rf}$ and microwave dielectric behavior of foods," The Journal of Microwave Power and Electromagnetic Energy, vol. 43, no. 2, pp. 13-23, 2016.

[9] S. Wang, M. Monzon, J. A. Johnson, E. J. Mitcham, and J. Tang, "Industrial-scale radio frequency treatments for insect control in walnuts. I: heating uniformity and energy efficiency," Postharvest Biology and Technology, vol. 45, no. 2, pp. 240-246, 2007.

[10] K. Sacilik and A. Colak, "Determination of dielectric properties of corn seeds from 1 to $100 \mathrm{MHz}$," Powder Technology, vol. 203, no. 2, pp. 365-370, 2010.

[11] X. Hu and P. Mallikarjunan, "Thermal and dielectric properties of shucked oysters," LWT- Food Science and Technology, vol. 38, no. 5, pp. 489-494, 2005.

[12] C. R. Paul, Introduction to Electromagnetic Compatibility, John Wiley and Sons, 2006.

[13] G. Tao and Q. Wang, "Research on arch method for testing the absorbing capability of absorbing materials," in PIERS Proceedings, pp. 244-248, 2009.

[14] M. C. Messia, T. Candigliota, and E. Marconi, "Assessment of quality and technological characterization of lactosehydrolyzed milk," Food Chemistry, vol. 104, no. 3, pp. 910-917, 2007.

[15] F. B. Mimouni, R. Lubetzky, S. Yochpaz, and D. Mandel, "Preterm human milk macronutrient and energy composition: a systematic review and meta-analysis," Clinics in Perinatology, vol. 44, no. 1, pp. 165-172, 2017.

[16] A. Kelimu, D. Felix da Silva, X. Geng, R. Ipsen, and A. B. Hougaard, "Effects of different dairy ingredients on the rheological behaviour and stability of hot cheese emulsions," International Dairy Journal, vol. 71, pp. 35-42, 2017.

[17] S. M. Matitsine, K. M. Hock, L. Liu, Y. B. Gan, A. N. Lagarkov, and K. N. Rozanov, "Shift of resonance frequency of long conducting fibers embedded in a composite," Journal of Applied Physics, vol. 94, no. 2, pp. 1146-1154, 2003.

[18] D. Fan, W. Ma, L. Wang et al., "Determining the effects of microwave heating on the ordered structures of rice starch by NMR," Carbohydrate Polymers, vol. 92, no. 2, pp. 1395-1401, 2013.

[19] D. Fan, W. Ma, L. Wang et al., "Determination of structural changes in microwaved rice starch using Fourier transform infrared and Raman spectroscopy," Starch - Stärke, vol. 64, no. 8, pp. 598-606, 2012. 

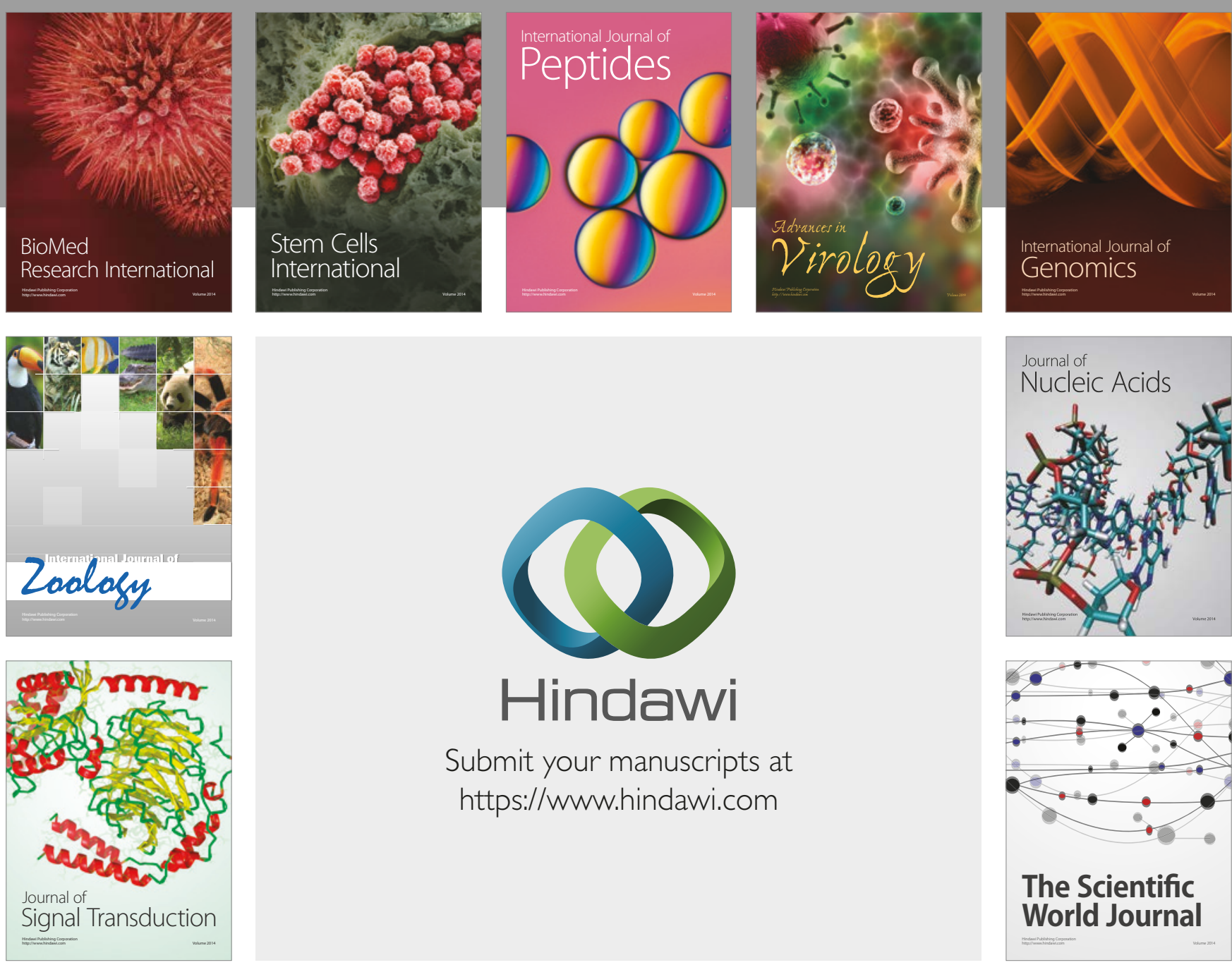

Submit your manuscripts at

https://www.hindawi.com
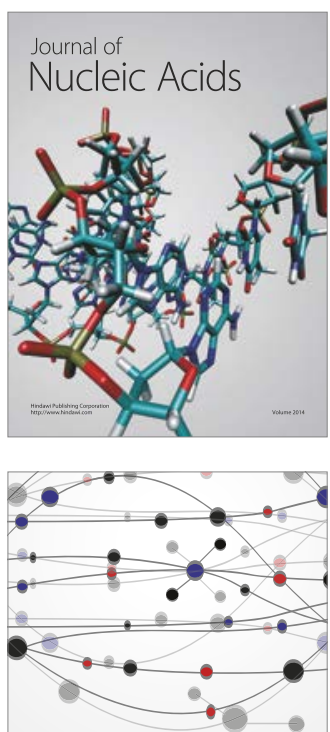

The Scientific World Journal

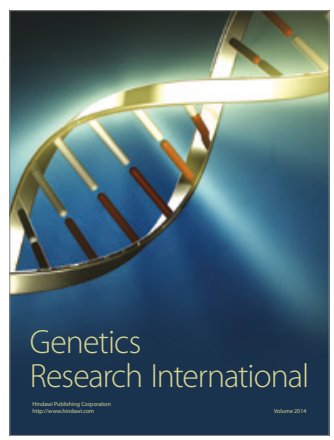

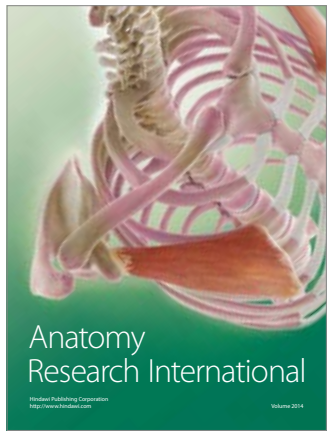

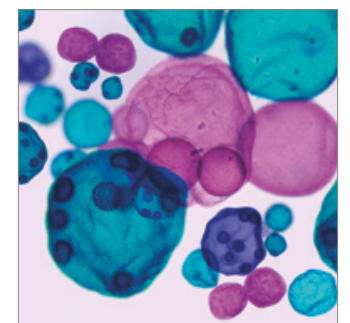

International Journal of Microbiology
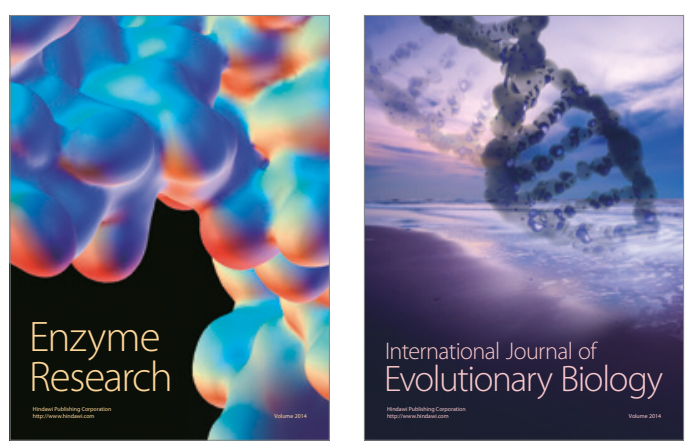
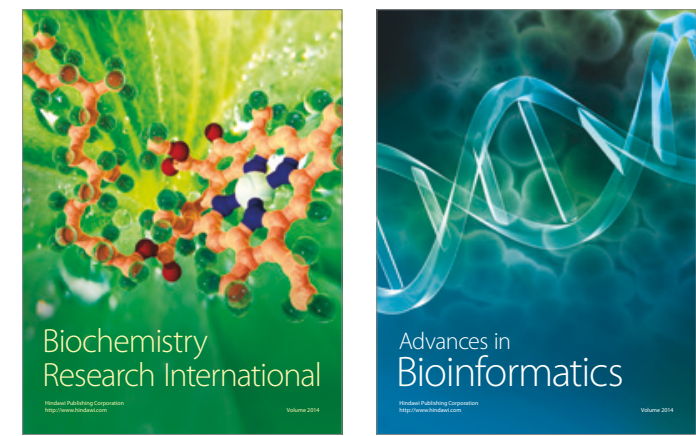

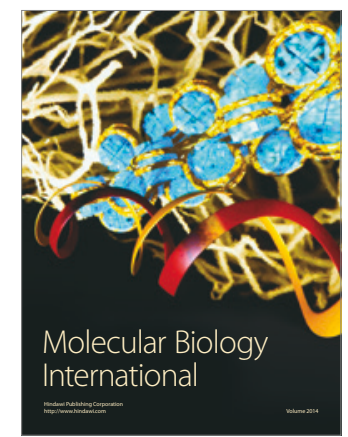

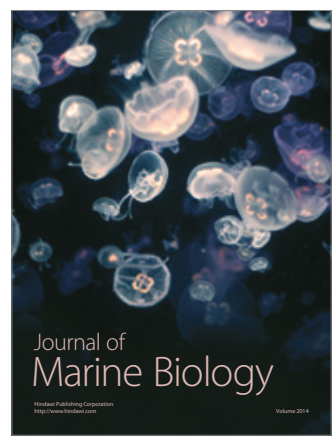

